\title{
Os percursos da etnomusicologia feminista nas últimas quatro décadas: uma visão de dentro por Ellen Koskoff
}

\author{
A Feminist Ethnomusicology: \\ Writing on Music and Gender. \\ KOSKOFF, Ellen.
}

New Perspectives on gender in music: University of Illinois Press, 2014.

O livro A Feminist Ethnomusicology: Writing on Music and Gender de Ellen Koskoff é uma referência para compreender alguns dos caminhos pelos quais trilhou a etnomusicologia feminista anglo-americana nos últimos quarenta anos a partir do ponto de vista de quem está intimamente implicada a essa trajetória. A carreira de Ellen Koskoff se desenvolveu em conjunto com a eminência desse campo, de modo que a autora é notadamente reconhecida como uma das pioneiras e mais prestigiadas personalidades no campo dos estudos de música e gênero, juntamente com Susan McClary (1991), Márcia Citron (1993), Suzanne Cusick (1994), para citar algumas pesquisadoras.

Para além de um compêndio da trajetória dos estudos de música e gênero, o livro pode ser lido como uma espécie de diário intelectual. Por meio da reedição de algumas de suas publicações - dos 13 capítulos 7 são artigos replicados enriquecidas com atualização de comentários, a autora mostra como seus posicionamentos pessoais, seus pontos de vista e suas abordagens epistemológicas foram se transformando ao longo de sua trajetória pessoal e intelectual em conjunto com o desenvolvimento da área. Ao mesmo tempo, o livro também pode ser lido como um diário íntimo de suas experiências como mulher, musicista e feminista. Em diversos momentos as discussões teóricas são transversalizadas por recordações vividas, narradas em forma de anedotas, nas quais a autora revela de modo franco seus sentimentos, reações, assombros e atitudes diante de certos fatos da vida cotidiana que envolveram questões de gênero.

Organizado em forma cronológica, o livro está dividido em três partes: parte I - 1976-1990 parte II - 1990-2000; e parte III - 2000-2012. Em cada uma delas, a autora mostra o diálogo que manteve com as correntes de pensamento de cada época, as deficiências e virtudes das abordagens predominantes e o desafio de aplicar, de transpor, de adaptar tais teorias para pensar a música enquanto objeto de estudo. Koskoff privilegiou dialogar com investigações cujo marco metodológico estão/estavam centrados no trabalho de campo e na etnografia musical, uma vez que suas próprias formulações de música e gênero resultaram deste tipo de empreendimento metodológico-epistemológico. Para ela, interações "face-a-face, conversando, rindo, ouvindo, gritando, comendo, fazendo música, resultam a maneira mais direta e eficaz de compreender os outros e suas músicas em relação a outros métodos de documentação" (Ellen KOSKOFF, 2014, p. XIII, tradução nossa). Assim, ao privilegiar o método etnográfico, a autora admite excluir grande parte das discussões de música e gênero baseadas em fontes documentais ou de revisão de literatura, como os estudos focados na importância histórica das mulheres, alguns estudos de música popular, e estudos de musicologia histórica e crítica.

Os três capítulos da primeira parte do livro (1976-1990) marcam a passagem da história compensatória das mulheres para uma conceituação mais abrangente de gênero como um sistema socialmente construído, regulador das formas de comportamento humano em contexto social, econômico e político (capítulo 1). Para tanto, a autora argumenta que, para abrir esse 
horizonte, o foco dos estudos de música e gênero precisa ser ampliado para além das artes ocidentais (capítulo 2). Com isso, Koskoff parte para o exame das relações de gênero em três contextos culturais, em perspectiva que ela denomina como cross-cultural': a ultra-ortodoxa cultura judaica Lubavitch; as práticas xamânicas na Coréia; e o grupo indígena norte-americano Iroquois Long-House (capítulo 3). Com base no trabalho de Sherry Ortner (1974), a autora sugere que estes três sistemas culturalmente diferentes situam as mulheres tanto dentro como entre ${ }^{2}$ natureza e cultura. Koskoff argumenta que a música nestes contextos está num plano muito semelhante ao das mulheres, e ambas derivam seu poder e sua eficácia precisamente por esta posição intermediária, compartilhando uma poderosa ambiguidade simbólica.

Os seis capítulos da segunda parte (19902000) marcam uma mudança no pensamento e na escrita da autora. Koskoff move-se de uma abordagem predominantemente teórica e comparativa em direção a uma abordagem de gênero em sistemas musicais e culturais específicos e, como isso, experimenta a profunda ambivalência entre diferença e semelhança, particularidade e comparação. O período em questão foi fortemente influenciado pela terceira onda feminista, pelas ideias pós-modernas, pósestruturais, pós-coloniais e pelo desconstrutivismo. As teorias de gênero definidas pelas primeira e segunda ondas feministas começam a ser contestadas em favor de uma nova subjetividade e multivocalidade. Embora autodeclarada como feminista da segunda onda, tais embates não deixaram de exercer influência no modo de pensar de Koskoff, de modo que, nesta seção, ela discute algumas ideias gerais que a levaram a repensar conceitos e relações básicas para os estudos de música e gênero a partir desta aproximação. A autora admite que as teorias generalizantes em perspectiva cross-cultural não conseguiram explicar as principais diferenças entre as culturas musicais, situação que the causara desconforto. Assim, os textos oscilam entre a necessidade de pensar mais seriamente em como lidar com as diferenças específicas (capítulos 4, 6, 7 e 9) enquanto busca soluções para elaborar algo significativo sobre questões mais gerais (capítulos 5 e 8).

Na terceira parte (2000-2012), a autora voltase para questões internas da etnomusicologia, antropologia e musicologia, centrando seu debate em discussões teóricas, epistemológicas e metodológicas no tocante aos estudos de música e gênero. O período em questão, marca- do por um feminismo cada vez mais multivocal, com agendas políticas diversas, por vezes, separadas, contrastantes e conflitivas, caminha para a construção de uma identidade complexa do feminismo e sem perspectiva de unificação. A autora exprime certa frustração pelo fato de os fundamentos da antropologia e da etnomusicologia manterem distância dos insights feministas das últimas décadas, estando a abordagem de gênero limitada ao interesse de grupos especializados. Para Koskoff, os avanços da etnomusicologia feminista das últimas décadas, além de terem pouco impacto na etnomusicologia como um todo, encontram obstáculos para a aceitação de forma ampla no interior da disciplina; situação análoga à antropologia feminista em relação ao campo da antropologia.

Além disso, Koskoff nota um desequilíbrio no avanço dos estudos de gênero e música ao comparar a etnomusicologia com sua irmã musicologia histórica. Etnomusicólogas(os) feministas, preocupadas(os) principalmente com as diferenças culturais e, dependendo do método de trabalho de campo, foram descobrindo e documentando diferentes entendimentos sociais e culturais de música e gênero que não puderam ser facilmente comparados ou generalizados, ao contrário de musicólogas(os) que, ao se voltarem para sua própria cultura e seus próprios dilemas teóricos, estavam em uma posição mais privilegiada para criar uma teoria feminista para a arte ocidental, especialmente a música popular. Isso se deve, em grande parte, porque tal teoria estava perfeitamente alocada dentro de quadros analíticos históricos e culturais ocidentais já definidos. Desse modo, ao mesmo tempo que aponta o trabalho de campo etnográfico como meio privilegiado de pensar música e gênero, Koskoff mostra que essa abordagem avança de forma mais lenta por estar implicada mais fortemente em dilemas éticos, morais e tendo que lidar com grandes diferenças culturais, as quais demandam a elaboração de abordagens teóricas, epistemológicas e metodológicas específicas.

Embora preocupada com a crescente multivocalidade e a pluralidade epistemológica no interior da etnomusicologia, Koskoff dialoga timidamente com as etnomusicologias produzidas em diferentes regiões do mundo, algumas das quais vêm ganhando mais espaço e legitimidade nos últimos anos no cenário internacional. Apesar do cenário anglo-americano ser notadamente o berço das discussões de música e gênero e a produção local se dar em escala 
virtuosamente maior do que em qualquer outra parte do mundo, partilho da preocupação de Lins Ribeiro (2014) acerca da necessidade de reconhecer as muitas produções periféricas, compreendê-las, apropriar-se delas e, principalmente, projetar o futuro da disciplina a partir de uma perspectiva cosmopolítica. Entretanto, a notória escassez de estudos etnomusicológicos com abordagem nas relações de gênero fora do marco anglo-americano torna sensivelmente problemática essa superação. No Brasil, até o presente momento, não há possibilidade concreta de desenhar uma etnomusicologia feminista como área de articulação intelectual e política. Na melhor das hipóteses, é possível apontar alguns estudos etnomusicológicos isolados que se propuseram a discutir questões de música e gênero, como Maria lgnez $\mathrm{C}$. Mello (2007; 2008); Laila Rosa (2010; 2013); Rodrigo C. S. Gomes (2008; 2010); Thalita Couto Moreira (2012). O grupo de estudos Feminaria Musical (Laia ROSA, Eric HORA e Laurisabel SILVA, 2013) da Escola de Música da Universidade Federal da Bahia, coordenado por Laila Rosa, é provavelmente o empreendimento mais próximo de uma etnomusicologia feminista brasileira. Entretanto, nota-se nos últimos anos iniciativas no Brasil para constituir um campo de estudos de gênero no interior amplo campo dos estudos musicais - inclua-se: musicologia histórica, etnomusicologia, estética, teoria e análise musical, composição, educação musical, música popular, performance, sonologia, entre outros. Um dos marcos dessa iniciativa foi a recente publicação de uma coletânea de artigos intitulada Estudos de Gênero, Corpo e Música: abordagens metodológicas (Isabel NOGUEIRA; Susan FONSECA, 2013), publicada pela Associação Nacional de Pesquisa e Pósgraduação em Música (ANPPOM). Além disso, destacam-se eventos como o I Encontro de Música e Gênero da Amazônia, realizado em setembro de 2015 na cidade de Manaus, organizado pela Universidade Estadual do Amazonas; e o I Encontro Internacional de Estudos de Gênero, Corpo e Música: representações, discursos e práticas, previsto para acontecer em meados de 2016, organizado em parceria com o Laboratório de Musicologia do Departamento de Música da Faculdade de Filosofia, Ciências e Letras de Ribeirão Preto/USP; o grupo Estudos em Corpo e Arte da Escola de Artes Ciências e Humanidades/ USP; e o Grupo de Pesquisa em Musicologia e Performance do Instituto de Artes/UFRGS.

Apesar de a obra ainda não ter sido traduzida e tampouco divulgada em âmbito nacional, $A$
Feminist Ethomusicology: Writing on Music and Gender de Ellen Koskoff, em seu conjunto, tem potencial para ampliar o interesse sobre o tema das relações de gênero meio musical brasileiro, bem como servir de inspiração para constituirmos nossa própria trajetória neste campo.

\section{Notas}

${ }^{1}$ Não encontrei uma tradução precisa para esse termo. Entre as possibilidades levantadas estão transcultural multicultural, intercultural, cultural comparada, mas nenhuma dessas me pareceu adequada, por isso, preferi manter o termo no idioma original.

${ }^{2}$ Both In and Between é a expressão usada pela autora. $O$ terceiro capítulo intitula-se: Both In and Between: Women's Musical Roles in Ritual Life.

\section{Referências}

CITRON, Marcia Judith. Genderand the Musical Canon. Cambridge: University Press, 1993.

CUSICK, Suzanne. "Feminist Theory, Music Theory, and the Mind/Body Problem". Perspectives of New Music, v. 32, n. 1, p. 8-27, winter 1994. GOMES, Rodrigo Cantos Savelli. "Relações de Gênero e Rock'n'roll: um estudo sobre as bandas femininas de Florianópolis". In: Secretaria Especial de Políticas Públicas para as Mulheres (Org.). $3^{\circ}$ Prêmio Construindo a Igualdade de Gênero - Redações e artigos científicos vencedores. Presidência da República. Brasília: Secretaria Especial de Políticas Públicas para as Mulheres, 2008, p. 134-148.

; PIEDADE, Acácio Tadeu Camargo. "Música, Mulheres, Territórios: uma etnografia da atuação feminina no samba de Florianópolis". Revista Música e Cultura, n. 5, p. 01-15, 2010.

KOSKOFF, Ellen. A Feminist Ethnomusicology: Writings on Music and Gender. Chicago: University of Illinois Press, 2014.

MCCLARY, Susan. Feminine Endings. Minnesota: University of Minnesota Press, 1991.

MELLO, Maria Ignez Cruz. "Relações de gênero e musicologia: reflexões para uma análise do contexto brasileiro". Revista Eletrônica de Musicologia, v. 11, setembro 2007. Disponível em: <http://www.rem.ufpr.br/ REM/ REMv1 1/14/14-mello-genero.html>. Acesso em: 12/02/2016

. "Os Cantos Femininos Wauja no Alto Xingu". In: MATOS, Cláudia Neiva de; TRAVASSOS Elizabeth; MEDEIROS, Fernanda (Orgs). Palavra Cantada: ensaios sobre Poesia, Música e Voz. Rio de Janeiro: 7Letras, 2008, p. 238-248.

MOREIRA, Talitha Couto. Música, materialidade e relações de gênero: categorias transbordantes. 2012. Dissertação (Mestrado em música-etnomusicologia). Programa de Pós-Graduação 
em Música da Universidade Federal de Minas Gerais, Belo Horizonte.

NOGUEIRA, Isabel Porto; FONSECA, Susan Campos (Orgs.). Estudos de gênero, corpo e música: abordagens metodológicas. Goiânia/Porto Alegre: ANPPOM, 2013.

ORTNER, Sherry. "Is Female to Male as Nature Is to Culture". In: ROSALDO, Zimbalist; LAMPHERE, Louise (Orgs.). Woman, Culture, and Society Stanford, Calif:: Stanford University Press, 1974, p. 67-87.

RIBEIRO, Gustavo Lins. "World Anthropologies: Anthropological Cosmopolitanisms and Cosmopolitics". Annual Review of Anthropology, vol. 43, p. 483-498, 2014.

ROSA, Laila. "Pode performance ser no feminino?". Ictus, v. 11, n. 2, 2010, p.83-99.

"Podem as subalternas cantar?: branquitude e racismo versus mulheres negras, cantos e performances no feminino da Jurema Sagrada". In: GARCIA, Antônia dos Santos; GARCIS, Raul Garcis Jr. (Orgs.). Relações de gênero, raça, classe e identidade social no Brasil e na França. Rio de Janeiro: Letra Capital, 2013, p. 121-142.

HORA, Eric; SILVA, Laurisabel. "Feminaria

Musical: grupo de pesquisa e experimentos sonoros". In: Anais do Seminário Internacional Fazendo Gênero 10: Desafios Atuais dos Feminismos. Florianópolis, UFSC, 2013. Disponível em: <http://www.fazendogenero.ufsc.br/10/ resources/anais/20/1385055525_ARQUIVO_Lai laRosa.pdf >. Acesso em 11/02/2016.

Rodrigo Cantos Savelli Gomes Universidade Federal de Santa Catarina, Florianópolis, SC, Brasi

676 Estudos Feministas, Florianópolis, 24(2): 0, maio/agosto/2016 